\title{
A Brief Talk about Camera Phone Photography in the Era of Digital Photography
}

\author{
Yang Zhi \\ Hunan University of Humanities, Science and Technology \\ Loudi, Hunan
}

\begin{abstract}
The development of the modern society and the advancement of science and technology provides people with more methods and channels to gain images. Digital photography, which used to be a method to obtain high quality pictures, begins pursuing more convenient operation and easier intelligent user experience. Meanwhile, the number of shutterbugs is increasing. Photography becomes increasingly closely related to people's life. An age of mass photography has come. With the lowered barrier to entry for photography, cameras, which were rare in the past, are necessities in the modern life. Now everyone can be a citizen journalist. With the constant renewal of smart phones, the level of camera phone photography has been significantly improved. Today, photography is entering a "micro" era. The size of photographic equipment is becoming increasingly smaller while the quality of images is maintained. Therefore, the scientific and technological aesthetics and aesthetic connotation presented by camera phone photography has become a force that can not be ignored in the modern society. This article mainly expounds the development trend of mobile phone photography through three angles: the actual effect of mobile phone photography, the commercial needs and the historical needs. And through the summary of the characteristics of mobile phone photography, it will provide new ideas for future photography creation.
\end{abstract}

Keywords-Digital photography; Camera phone photography; Spread; Development trends

\section{AN OVERVIEW OF CAMERA PHONE PHOTOGRAPHY}

It has been over 100 years since the invention of photography. With the development of science and technology, the sensitive materials has become electronic sensitive chips today from silver compounds in early days. The three scientific and technological revolutions has tremendously changed human life and production in every aspect. The change of photography, from traditional to modern, is a quite important aspect [1]. In early 1990s, computers, once tools in laboratories, entered public life. Nowadays, smart phones become a typical representative of the modern technological form. People can chat, paint, pay, watch movies, play video games and use other entertainment apps on their phones. In the era of camera phone photography, the popularized photography make everyone a photographer [2].

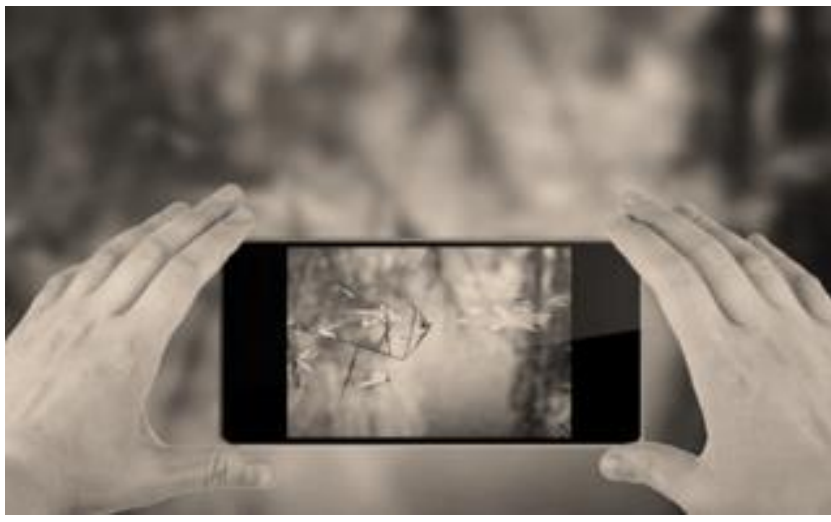

Fig. 1. Landscape photography with smart phone(online picture)

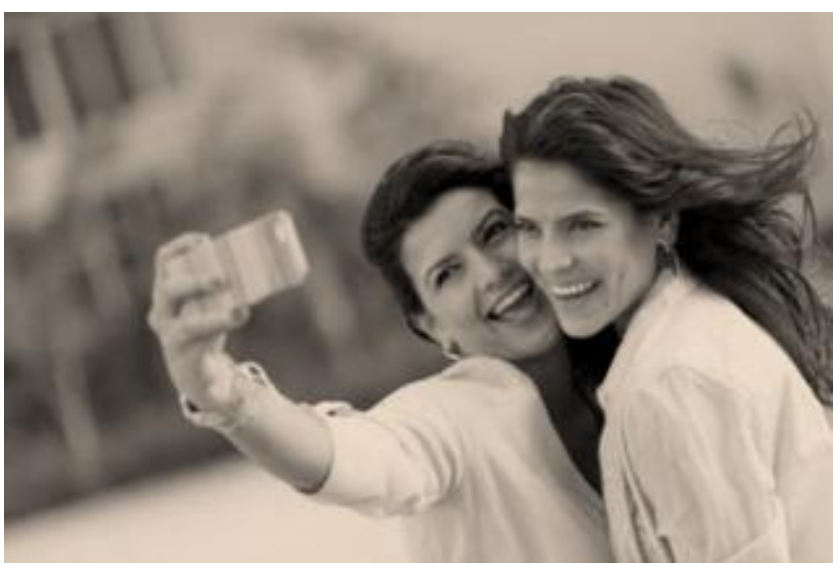

Fig. 2. Selfie with smart phone(online picture)

\section{THE EFFECTIVENESS OF CAMERA PHONE PHOTOGRAPHY IN DISSEMINATION}

With the emergence of Internet technology and We-Media, the official media is not the only way to get information. Expressing thoughts and opinions through posting texts and pictures whenever and wherever possible has become a trend in the modern society, such as the rapid rise of WeChat Moments and the prosperity of various mobile games and apps [3]. The development of phone cameras rouses the masses' interests for photography, which makes WeChat Moments an important method to record life through shooting and posting texts. People have accustomed to express their emotions and 
feelings when they are on travel, enjoy cuisines and go hiking together with their friends. At the same time, they can also know the current situation of their friends the do not meet frequently and feel the outside world through Moments. In this fast-paced world, people are increasingly dependent on camera phone photography [4]. In both cities and the countryside, whenever and wherever you are, camera phone shooting snaps one wonderful moment after another. The relationship between people and photography is changing. People find pleasure in the process of shooting. Everyone can record his life through taking photos with his phone, freeing themselves from the sense of ceremony brought by traditional photography and gaining joy in the process of recording.

\section{COMMERCIAL DEMANDS OF CAMERA PHONE PHOTOGRAPHY IN DISSEMINATION}

In 1950s, experimentalist photographer Laszlo MoholyNagy ever wildly predicted: "Illiterate people will not be able to shoot." With the rise of Internet, many e-commerce platforms also conduct propaganda with photos shot by phones [5]. One can create economic values just with a smart phone, which is testified by the emergence of WeChat business and the shopping boom on Tabao. Social software like Weibo and WeChat are not just chat software. They, with both one-to-one and interactive ways of communicating, have become the communication platform between businesses and customers. For instance, web pages can be shared between WeChat and Weibo and users of Taobao can share commodities they like to their friends on WeChat, Weibo and QQ. Usually, contents containing pictures are more likely to be disseminated, clicked, reviewed and forwarded. Everyone can join camera phone photography. Photographers can create and update their works whenever and whatever possible, catching eyes and attracting potential customers. The emergence of camera photography brings convenience and diversity to the generation of economic benefits [6]

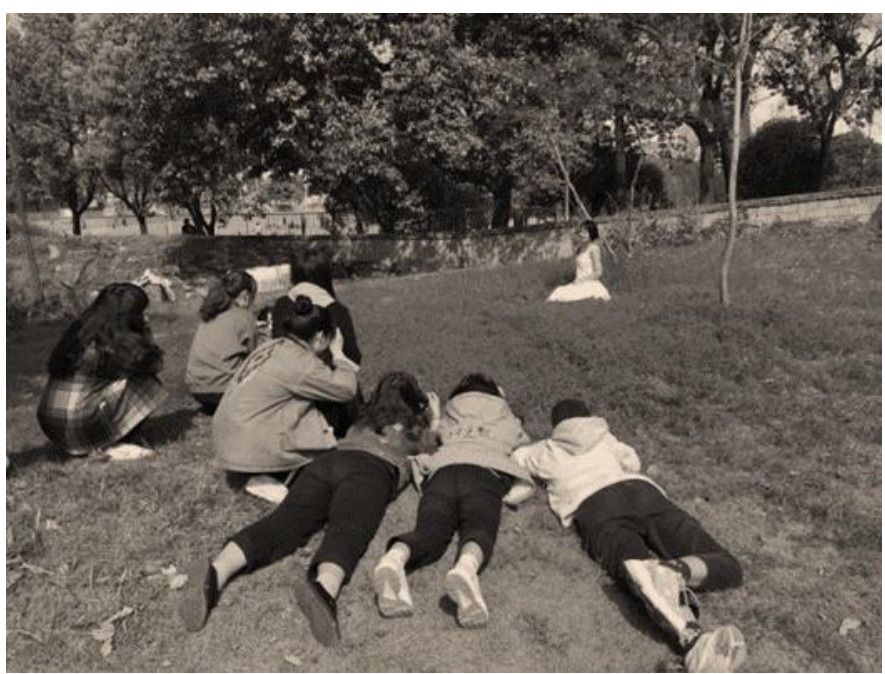

Fig. 3. Taking a portrait in a class (picture by the author)

\section{THE HISTORICAL SIGNIFICANCE OF CAMERA PHONE PHOTOGRAPHY IN DISSEMINATION}

In the era of camera phone photography, every phone users can become an artist and a recorder of history. Many on-thespot photos handed down from the past can be discovered but not sought. However, the development of intelligent camera phone photography has completely changed this. Sharpness and viewfinding is not important. What matters is that chance events are recorded by images. For example, significant and influential events can be recorded with phones if there is no specialized equipment. Some conflicts, political events or disasters can also be recorded with smart phones. Major events play a key role in human's life and development, so the historical value cannot be ignored.

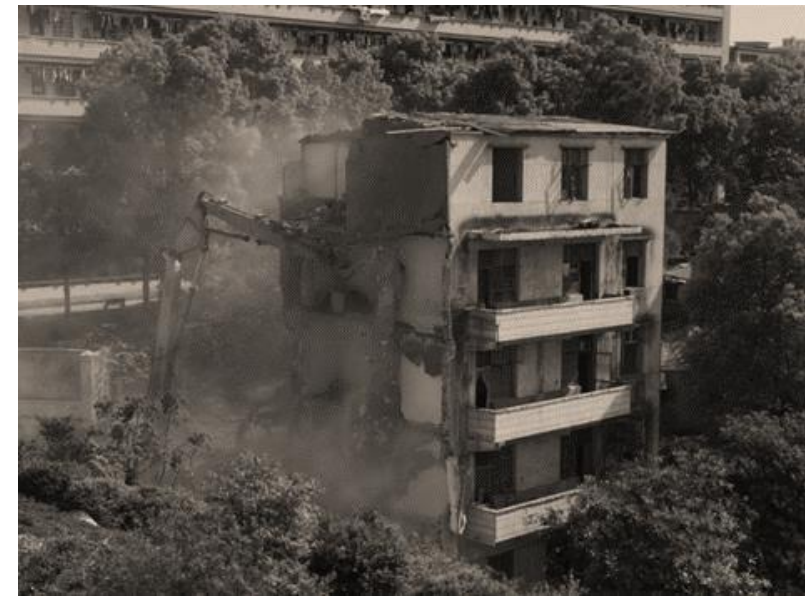

Fig. 4. A disappearing building (picture by the athor)

\section{IMPORTANT EFFECTIVENESS CAMERA PHONE PHOTOGRAPHY}

\section{A. The momentary recording of camera phone photography}

In the modern society, the equipment for shooting is not important anymore. In this age of mass photography, phone shooting is one of people's lifestyles. One can conveniently snap moments in his life. The picture on the right, in which two cleaners were chatting and resting, was shot by the present writer when he was taking a walk. The shooting was a random action happened in a certain time and space. Scenes like this can hardly be attained by posed photography. The biggest advantage of camera phone shooting is that when you meet a very interesting thing in your life, you do not need certain digital cameras and need not think about which poses are more suitable. You can show the effectiveness of pictures and better restore the space just by record existing scenes [7]. 


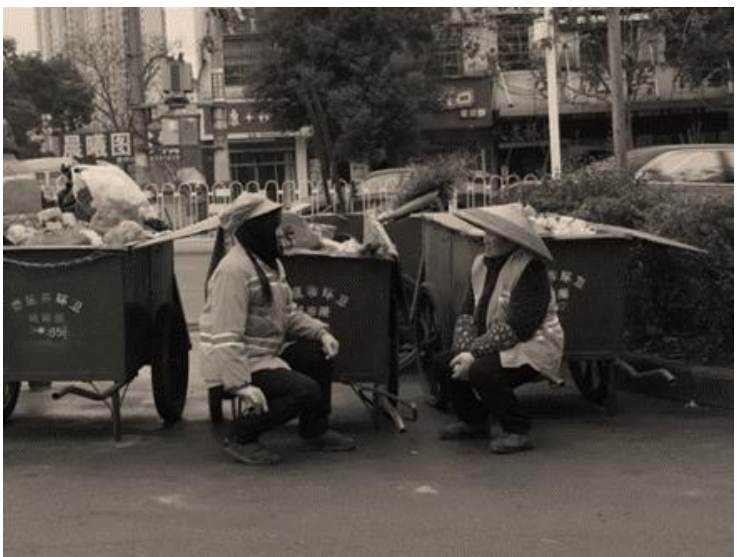

Fig. 5. Two cleaners chating with each other (picture by the author)

\section{B. The choice of composition of camera phone photography}

Composition of camera phone photography and digital camera photography has something in common. But there are also differences between them. For example, when composing, camera phone photography will classify and compose according to time and space. Digital cameras, likewise, can compose gradations of pictures freely. However, compared with traditional film cameras, which can not compose freely and mainly reflect an abstract method of composition, the composition of camera phone photography is various. You can delete and modify the photos you not satisfied with. Specific methods include leaving copy space, trichotomy and the symmetric method.

\section{The diagonal mode of camera phone photography}

With the advancement of science and technology, the shooting function of smart phones become increasingly powerful. For instance, the technology focus modes of iPhone and HUAWEI phones are quite mature. When you deliberately shoot under the defocussed mode, you can press the shutter of your phone camera and then you can get a picture that is defocussed.

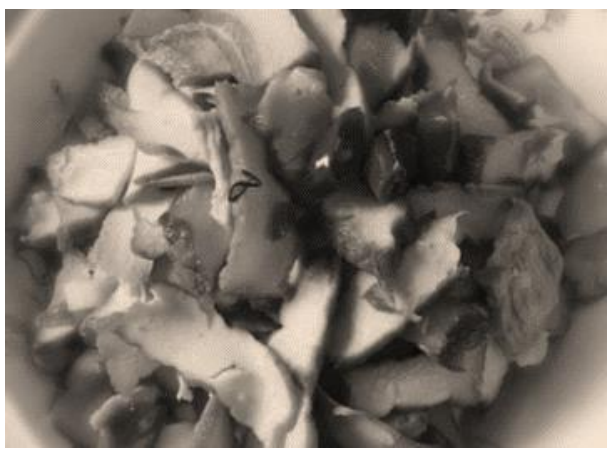

Fig. 6. Food (picture by the author)

\section{Exposure modes of camera phone photography}

Compared with the film mode traditional camera photography, camera phone photography today tend to record sensitively with fast-paced operation. Nowadays, image sensors of phone cameras have adopted Exmor RS CMOS, whose principle is similar to that of backside illuminated sensors (BIS). The only difference between them is that the former moves the light receptor to below the light receiving area in order to ensure that the process of light receiving is not affected, whereby allowing the camera to receive real light outside accurately. When it comes to exposure modes, the starting speed of phone cameras is increasingly fast. Under the normal modes Pixel phone presented by Google ranks first at 1.1 seconds and iPhone comes the second at 1.13 seconds. The gap between the first two is just 0.03 second. In 2017, iPhone7 Plus adopted dual-camera technology for the first time. The diaphragm of the wide angle lens was F1.8, while that of the telephoto one was F2.8, whose equivalent focal length was about $56 \mathrm{~mm}$. All pictures in this article are shot by photographers in their daily life.

\section{CONCLUSION}

Photography, either traditional or camera phone photography, is to record beautiful time and retain wonderful moments. With the arrival of the era of smart phones, the popular craze of "mass photography" is coming. Camera phone photography is gradually changing people's lifestyles. It can share pictures on social networks, show photos of higher qualities and modify pictures by apps. Momentary recording with camera phones, and, together with camera software, creating works different from that shot with digital cameras will allow people find much creative beauty in camera phone photography, which will be a key challenge for creation in camera phone photography in the future.

\section{REFERENCES}

[1] Xue, Manjun. "Creative Studies of the Design of Visual Communication Based on Digital Technology." Literatures (Theory ), 2011.

[2] Fang, Jianhua. "From 'Photography as Art' to 'Art as Photography' -Studies on the History of Visual Cultures." Journal of Xidian University (Social science ), 2014. 247-249.

[3] Wu, Tie. "Inseparable Light and Shadow --- A Brief Talk about Photography and Designs." The Guide of Science \& Education, 2016.

[4] Zhou, Hu. "On Camera Phone Photography and Photographic Creation in the Visual Age." Journal of Huaiyin Teachers' College, 2015.

[5] Wang Z, Chao K T. Analysis of the Current Development Situation of China Concept Photography in the Digital Photography Era[J]. Art \& Design, 2014

[6] Goma S, Aleksic M, Georgiev T. Camera Technology at the dawn of digital renascence era [J]. 2010, 45(2):847-850.

[7] Brown G R. The Blue Line on Thin Ice: Police Use of Force Modifications in the Era of Cameraphones and YouTube[J]. British Journal of Criminology, 2016, 56 (2). 